(c) 2019 Universidad Nacional Autónoma de México, Facultad de Estudios Superiores Zaragoza.

Este es un artículo Open Access bajo la licencia CC BY-NC-ND (http://creativecommons.org/licenses/by-nc-nd/4.0/).

TIP Revista Especializada en Ciencias Químico-Biológicas, 22: 1-11, 2019.

DOI: $10.22201 /$ fesz.23958723e.2018.0.160

\title{
Papel de las hormonas vegetales en la regulación de la autofagia en plantas
}

\author{
Helena Porta y Gladys Jiménez-Nopala \\ Departamento de Biología Molecular de Plantas, Instituto de Biotecnología, Universidad \\ Nacional Autónoma de México, Avenida Universidad \# 2001, Colonia Chamilpa, Cuernavaca, \\ Morelos 62210, México. E-mail: gladysjn@ibt.unam.mx; helena@ibt.unam.mx
}

\begin{abstract}
RESUMEN
Las hormonas vegetales son moléculas señalizadoras que se localizan en los diferentes tejidos de una planta y en cantidades específicas de acuerdo al proceso que regulan. Los cambios en la concentración y distribución de las hormonas vegetales modulan el desarrollo y las respuestas al estrés biótico y abiótico.

La autofagia, que significa autodigestión, es un mecanismo que degrada los componentes dañados o tóxicos que surgen del metabolismo, con la finalidad de reciclarlos y mantener la salud de la célula. En este proceso se forman vesículas de doble membrana llamadas autofagosomas, las cuales encierran la carga dañada o no deseada, que posteriormente se deposita para su degradación en la vacuola de donde la célula recupera aminoácidos, lípidos y proteínas. Se ha observado una confluencia entre las hormonas vegetales y la autofagia durante el desarrollo y el crecimiento, la senescencia y la muerte celular programada.

En esta revisión repasamos los avances en la comprensión del papel de las hormonas vegetales involucradas en la modulación de la autofagia en las plantas.
\end{abstract}

Palabras Clave: autofagia, hormonas vegetales, desarrollo y estrés.

Role of plant hormones in the regulation of autophagy in plants

\begin{abstract}
Plant hormones are signaling molecules that are localized in different plant tissues and in specific amounts according to the process that they regulate. Changes in the concentration and distribution of plant hormones modulate the development and responses to biotic and abiotic stress.

Autophagy, which means self-digestion, is a mechanism that degrades damaged or toxic components that arise from the metabolism, in order to recycle them and maintain the health of the cell. The most studied type of autophagy is macroautophagy which will be referred in this review as autophagy. In this process, double membrane vesicles called autophagosomes are formed to enclose damaged or unwanted cell cargo, which is later deposited for its degradation into the vacuole, from where the cell recovers amino acids, lipids and proteins. Indeed, communication between plant hormones and autophagy has been observed during development and growth, senescence and programmed cell death. In this review we discuss the advances in the understanding of the role of plant hormones involved in the modulation of autophagy in plants.
\end{abstract}

Key words: autophagy, plant hormones, stress and development.

Nota: Artículo recibido el 10 de agosto del 2018 y aceptado el 13 de enero del 2019. 


\section{INTRODUCCIÓN}

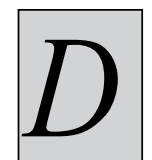

\section{LAS HORMONAS VEGETALES}

ebido a la vida sésil de las plantas, éstas cuentan con una capacidad enorme para regular su crecimiento tanto en el desarrollo como en respuesta a las señales ambientales, las cuales están mediadas por las hormonas vegetales. Las hormonas vegetales son moléculas sintetizadas por la planta que controlan la gran mayoría de los procesos fisiológicos y bioquímicos como lo son la división celular, el crecimiento, la diferenciación de los órganos aéreos y de las raíces. También, regulan la embriogénesis, la germinación de las semillas, la floración, la formación del fruto, la caída de las hojas y la senescencia (Jiménez, 2005; Buchanan et al., 2015; Finkelstein, 2010; Santner \& Estelle, 2009). Además, se inducen en respuesta a la invasión por patógenos (Yoshimoto et al., 2009). Hasta el momento, se han descrito 11 tipos de hormonas vegetales de las cuales seis de ellas se relacionan con la autofagia: el ácido abscísico (ABA; Wang et al., 2015), el etileno (Shibuya et al., 2013) las giberelinas (GA; Kurusu et al., 2017), las auxinas (IAA, ácido indol-3-acético; Bögre et al., 2013), las citocininas (Kurusu et al., 2017) y el ácido salicílico (SA; Yoshimoto et al., 2009). Por el contrario, los brasinoesteroides, los jasmonatos, las estrigolactonas, las poliaminas y el óxido nítrico no se han relacionado con la autofagia hasta el momento.

\section{LA AUTOFAGIA}

La autofagia es un proceso catabólico conservado en todas las células eucariotas por la cual el material citoplasmático se descarga, en el interior del lisosoma en animales o en el interior de la vacuola en plantas y levaduras, para su descomposición y reciclamiento (Parzych \& Klionsky, 2014).

La macroautofagia (en lo subsecuente referida como autofagia) es el tipo de autofagia más estudiado tanto en levaduras como en animales y en plantas. Esta es la vía por la cual el material citoplasmático dañado se secuestra en vesículas de doble membrana, llamadas autofagosomas, que transportan su contenido para su degradación en el lisosoma en animales o en la vacuola en plantas y levaduras (Yang \& Bassham, 2015). En condiciones normales de crecimiento, la autofagia ayuda al mantenimiento celular, ya que degrada organelos dañados o proteínas mal plegadas (Yang \& Klionsky, 2009). Debido a esto se considera que la autofagia es principalmente un mecanismo citoprotector. En situaciones de estrés su función principal es mantener la vida de la célula hasta que el estrés termine. El primer organismo en el que la autofagia se describió a nivel molecular fue la levadura Saccharomyces cerevisiae. Con el uso de análisis genético se identificó a los genes esenciales para la formación del autofagosoma denominados ATG (Autophagy Related Genes; Figura 1; Parzych \& Klionsky, 2014). La mayoría de los genes $A T G$ se conservan en plantas y en mamíferos, lo que sugiere que la maquinaria de la autofagia es esencialmente la misma en las levaduras y los eucariotas superiores (Tablas I y II; Yang \& Bassham, 2015).

\section{Morfología Y MAQUINARIA DE LA AUTOFAGIA}

La característica morfológica que hace a la autofagia única, comparada con otros procesos de tráfico intracelular mediado por vesículas, es la formación de novo de vesículas de doble membrana que secuestran la carga del citoplasma para su degradación en la vacuola. En las plantas la fuente principal de lípidos para la formación de autofagosomas es el retículo endoplásmico (Zhuang et al., 2017).

Debido a que se conoce el genoma de Arabidopsis thaliana, se sabe que la mayoría de los genes $A T G$ están conservados en este sistema biológico. Así mismo se ha demostrado que la mayoría de estos genes conservan su función y regulación comparados con S. cerevisiae (Avin-Wittenberg et al., 2012).

La autofagia se activa debido a señales del desarrollo y/o a la disminución de nutrientes con la inactivación del complejo TOR. TOR es un regulador negativo de la autofagia que la bloquea mediante la hiperfosforilación de ATG13, evitando así su asociación con ATG1. Una vez activada la autofagia, el complejo TOR se disocia de ATG13, lo que promueve el ensamblaje del complejo ATG1, a través de la desfosforilación de ATG13 y su unión a ATG1 (Dobrenel et al., 2016; Figura 1 , etapa 1).

Una vez activo el complejo ATG1 se promueve la nucleación de la maquinaria de la autofagia en el sitio de ensamblaje. El complejo PI3K de clase III, conformado por VPS34, VPS15, ATG6 y ATG14, fosforila al fosfatidilinositol (PI) para generar fosfatidilinositol-3-fosfato (PI3P), lo que ocasiona que una región de la membrana, llamada fagóforo, se invagine hacia al citosol donde se van concentrando los complejos de la autofagia (Yang \& Klionsky, 2009). Conjuntamente, el complejo ATG9 compuesto por ATG9, ATG18 y ATG2, recluta porciones de la membrana para la expansión del fagóforo (Yang \& Basham, 2015; Figura 1, etapa 2).

El siguiente paso se centra en una ruta de conjugación análoga a la ubiquitinación que decora al fagóforo con la proteína ATG8 y que contribuye en la expansión del autofagosoma. El proceso de conjugación implica dos procesos que generan un conjugado de ATG8 con el lípido fosfatidiletanolamina (PE), ATG8-PE, que es la forma funcional en la autofagia. Para la formación de ATG8-PE, primero la cisteína proteasa ATG4, corta el C-terminal de ATG8 y expone un residuo específico de glicina. La glicina expuesta del ATG8 se activa por acción de la ATG7, que es una enzima tipo E1 dependiente de ATP; posteriormente el ATG8 activado se transfiere a la ATG3, que es una enzima tipo E2, para conjugarlo covalentemente con PE, a través de la ligasa ATG5-ATG12-ATG16. El ensamblaje de esta ligasa requiere de la conjugación de ATG12 con ATG5, 


\section{Etapas del proceso Complejos proteicos}

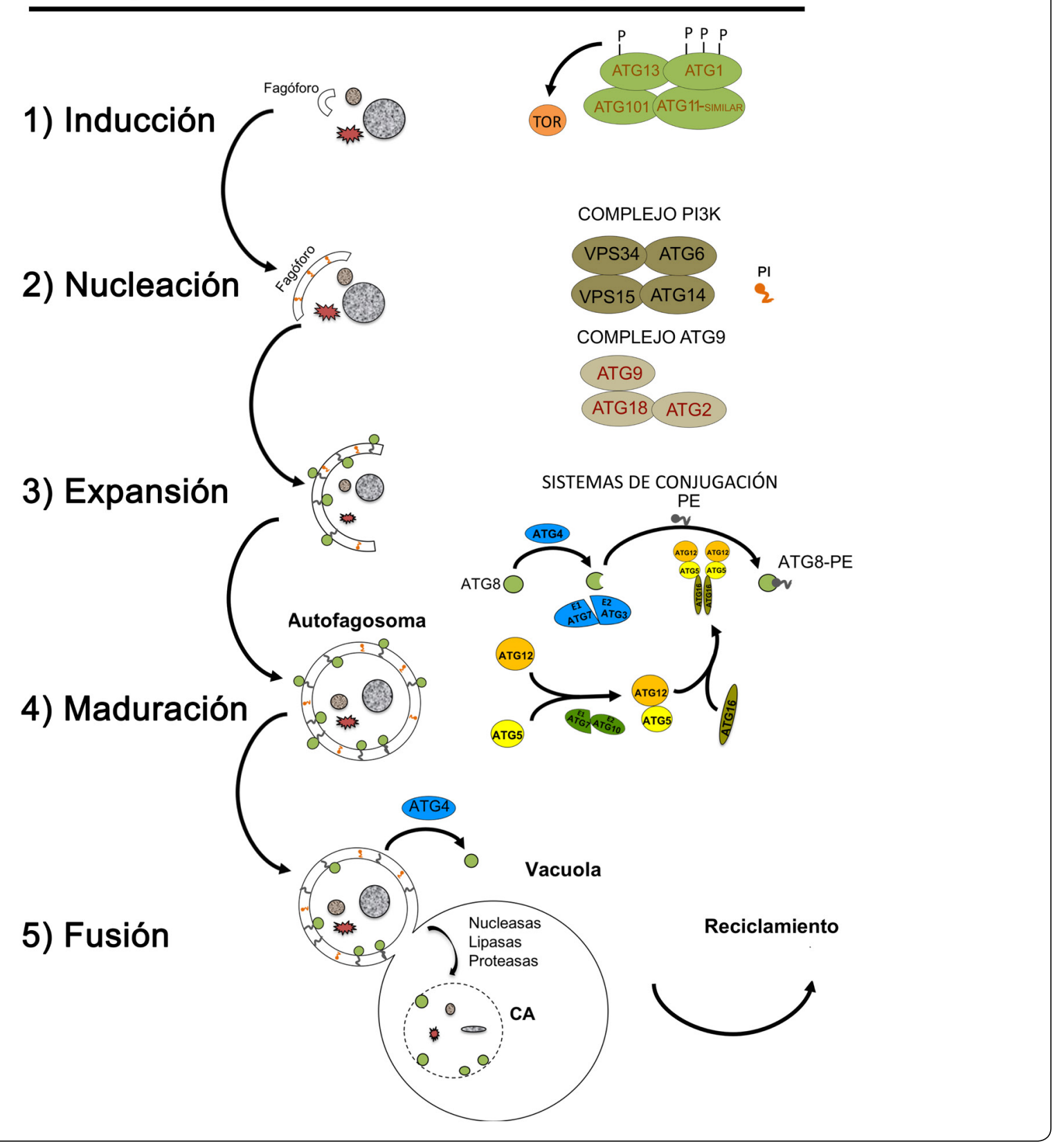

Figura 1. Esquema general de la autofagia de Arabidopsis thaliana. En condiciones nutricionales favorables, la cinasa TOR y el complejo ATG1 se encuentran asociados, ya que TOR mantiene hiperfosforilada a la ATG13, de esta manera se inhibe la autofagia. Al ser activada la autofagia las proteínas denominadas ATG se agrupan en diferentes complejos proteicos que funcionan en las diferentes etapas del proceso en la formación y degradación del autofagosoma y su carga. 1) En condiciones adversas como la carencia de nutrientes, estrés biótico o abiótico, la autofagia se activa y TOR se inhibe, separándose del complejo ATG1, lo que promueve la desfosforilación de ATG13; esto permite que se inicie la nucleación del proceso. 2) Durante la nucleación, el complejo PI3K fosforila al Fosfatidilinositol (PI) para generar Fosfotidilinositol-3-fosfato (PI3P) y dar origen a la formación del fagóforo. A su vez, el complejo ATG9 se encarga de reclutar porciones de lípidos para el crecimiento del fagóforo y formar el autofagosoma. 3) Durante la expansión del autofagosoma los dos sistemas de conjugación, tipo ubiquitinación, actúan. Primero se forma el complejo ATG5-ATG12-ATG16 con ayuda de las proteínas ATG7 y ATG10. Paralelamente, a la proteína ATG8 se une el lípido fosfatidiletanolamina (PE), con ayuda de las proteínas ATG4, ATG7, ATG3 y el complejo ATG5-ATG12-ATG16, para poder integrarse a la membrana del autofagosoma. 4) La maduración del autofagosoma se da una vez que el fagóforo se cierra por completo y se forma la vesícula de doble membrana. 5) Durante la fusión, la membrana externa del autofagosoma se une con la membrana de la vacuola y la membrana interna junto con su contenido (cuerpo autofágico, CA) se degradan en el ambiente lítico de la vacuola. Las moléculas derivadas se reciclan al citoplasma. Fuente: Elaboración propia. 


\begin{tabular}{|c|c|c|c|}
\hline Complejo & S. cerevisiae & A. thaliana & Función en $S$. cerevisiae \\
\hline & TOR1 & AtTOR $1 *$ & $\begin{array}{l}\text { Ser/Thr proteína cinasa, coordinadora central de regulación por } \\
\text { nutrientes, estrés y energía. } \\
\text { Regulador negativo de la autofagia }\end{array}$ \\
\hline & Complejo & ATG1 & \\
\hline \multirow[t]{3}{*}{ Iniciación } & $\operatorname{Atg} 13$ & AtATG13a y b* & Necesario para la actividad de ATG1 \\
\hline & $\operatorname{Atg} 17$ & no identificada & Proteína de andamiaje \\
\hline & Atg20 & AtATG20 & Proteína de unión a PI3K clase III \\
\hline \multirow{5}{*}{$\begin{array}{l}\text { Iniciación, } \\
\text { Nucleación }\end{array}$} & Atg1 & AtATG1a-c, t & Ser/Thr proteína cinasa \\
\hline & Complejo & PI3K & \\
\hline & VPS15 & AtVPS15* & Ser/Thr proteína cinasa, modula la formación del complejo \\
\hline & VPS34 & AtVPS34* & Fosfatidilinositol 3-cinasa \\
\hline & ATG14 & no identificada & Une VPS34 con ATG6 \\
\hline \multirow[t]{7}{*}{ Nucleación } & Atg6 & AtATG6* & Señalización del fosfatidilinositol. \\
\hline & Complejo & ATG9 & \\
\hline & $\operatorname{Atg} 2$ & AtATG2* & Interacciona con ATG18; recluta ATG9 al fagóforo \\
\hline & $\operatorname{Atg} 18$ & AtATG18a-h* & Se une al fosfatidilinositol y se requiere para la autofagia \\
\hline & Atg9 & AtATG9* & Proteína membranal acarreadora de lípidos. \\
\hline & $\operatorname{Atg} 27$ & no identificada & $\begin{array}{l}\text { Proteína integral de membrana requerida para el movimiento de } \\
\text { ATG9 }\end{array}$ \\
\hline & Sistemas & de conjugación & \\
\hline \multirow[t]{7}{*}{ Elongación } & Atg3 & AtATG3* & Enzima tipo E2, conjuga fosfatidilinositol con ATG8. \\
\hline & $\operatorname{Atg} 4$ & AtATG4a-b & Cys proteasa, corta ATG8 en el C-terminal, expone una Serina \\
\hline & $\operatorname{Atg} 7$ & AtATG7* & Enzima tipo E1, corta ATG8 y ATG12. \\
\hline & $\operatorname{Atg} 5$ & AtATG5* & Se conjuga con ATG12 \\
\hline & $\operatorname{Atg} 10$ & AtATG10* & Enzima tipo E2, conjuga ATG5 con ATG12. \\
\hline & $\operatorname{Atg} 12$ & AtATG12a-b* & Proteína conjugada a ATG5 por ATG10 \\
\hline & $\operatorname{Atg} 16$ & no caracterizada & Unión no-covalente al complejo ATG5-ATG12 \\
\hline $\begin{array}{l}\text { Elongación, } \\
\text { Maduración }\end{array}$ & Atg8 & AtATG8a-i & Proteína conjugada al fosfatidilinositol \\
\hline
\end{tabular}

Tabla I. Comparación de los complejos de la autofagia entre Saccharomices cerevisiae y Arabidopsis thaliana. * plantas-RNAi o con inserciones de T-DNA; minúsculas, isoformas. (Modificado de Yoshimoto, 2012 y Yang \& Bassham, 2015).

mediada por ATG7 y ATG10, que son enzimas de conjugación tipo E1 y E2, respectivamente. Este conjugado ATG12ATG5 se une a un dímero de la proteína ATG16, formando el complejo ATG5-ATG12-ATG16 el cual tiene la función de una ligasa tipo E3 que finalmente promueve la lipidación de ATG8 con PE para su unión al fagóforo (Marshal \& Viestra, 2018; Figura 1, etapas 3 y 4).

El complejo ATG8-PE decora la membrana del fagóforo en expansión y ayuda a sellar la vesícula. A esta vesícula de doble membrana se le conoce como autofagosoma. Eventualmente, las moléculas de ATG8-PE que recubren la membrana externa del autofagosoma se deslipidan por acción de la ATG4 y se liberan para su reutilización, mientras que los ATG8-PE atrapados en la membrana interna se degradan en la vacuola (Yoshimoto et al., 2004; Figura 1, etapa 5).

Una vez formados los autofagosomas, se transportan a la vacuola, utilizando la red de microtúbulos (Tabla II). Los autofagosomas se fusionan con el tonoplasto liberando así el cuerpo autofágico, formado por la membrana interna del autofagosoma y su carga, que finalmente se degrada por una 


\begin{tabular}{|l|l|}
\hline $\begin{array}{l}\text { ARP2/3; } \\
\text { NAP1 }\end{array}$ & $\begin{array}{l}\text { Biogénesis del autofagosoma; nucleación } \\
\text { de la actina }\end{array}$ \\
\hline SH3P2 & Estimula la curvatura del fagóforo \\
\hline $\begin{array}{l}\text { ESCRT; } \\
\text { RAB7 } \\
\text { FYCO }\end{array}$ & $\begin{array}{l}\text { Posiblemente asociados al transporte del } \\
\text { autofagosoma en los microtúbulos }\end{array}$ \\
\hline v-SNARE & Fusión al tonoplasto \\
\hline $\begin{array}{l}\text { FREE1 } \\
\text { CFS1 }\end{array}$ & $\begin{array}{l}\text { Transporte y fusión del autofagosoma con } \\
\text { VPS2.1 } \\
\text { EXO70B1 }\end{array}$ \\
\hline VPEg & Proteasa tipo-caspasa, activa zimógenos \\
\hline
\end{tabular}

Abreviaturas: ARP2/3, proteína 2/3 relacionada a la actina; NPR1, proteína asociada a NCK; SH3P2, Proteína 2 con un dominio SH3; ESCORT, complejo de clasificación endosomal requerido para el transporte; v-SNARE, factor vesicular soluble sensible a la N-etilmaleimida unido al receptor de proteína; FYCO, proteínas con dominio coil-coil.

Tabla II. Otras proteínas que participan en el proceso de la autofagia en plantas.

serie de hidrolasas vacuolares activas contra lípidos, proteínas, ácidos nucleicos y carbohidratos (Marshal \& Viestra, 2018; Figura 1, etapa 5).

\section{LA AUtofagia en PLANTaS}

La autofagia es un proceso esencial para la célula y participa a lo largo del desarrollo de las plantas. Con el estudio de mutantes deficientes en los genes $A T G$ en la planta modelo Arabidopsis se confirmó que las proteínas ATG se requieren para su correcto desarrollo, por ejemplo, en las mutantes atg la senescencia y la floración se aceleran; producen menos semillas que las plantas silvestres y en condiciones de deficiencia de Nitrógeno, las raíces son más largas que las de la planta silvestre. Estos cambios se atribuyen a un ineficiente reciclamiento de nutrientes (Bassham et al., 2006). La autofagia se activa en procesos como: la formación de los pelos radiculares y la elongación de la raíz (Bassham et al., 2006, Inoue et al., 2006, Yano et al., 2007); durante la germinación del polen (Fujiki et al., 2007); durante la respuesta inmune innata (Hayward et al., 2009); en la diferenciación de las traqueidas (Kwon et al., 2010) en el desarrollo de embriones (Bozhkov et al., 2005), en el desarrollo del tubo polínico, durante la eliminación del estigma y en el establecimiento de la forma de las hojas (revisado en: van Doorn \& Woltering, 2005); también se encarga de degradar las mitocondrias dañadas (Li et al., 2014) y los cloroplastos durante la senescencia (Wada et al., 2009); participa en la obtención de energía durante la noche a través de la degradación del almidón (Izumi et al., 2013a), mediante la invaginación directa de las SSGL (Small Starch Granulelike structure), que se exportan desde los cloroplastos a través de los estrómulos y ya en el citoplasma los secuestran los autofagosomas para su degradación en la vacuola (Wang \& Liu, 2013) y en la respuesta al estrés por falta de nutrientes (Xiong et al., 2005, Rose et al., 2006).

La autofagia se induce en la respuesta al estrés biótico regulando la respuesta hipersensible promovida por los patógenos (Lai et al., 2011). En el estrés abiótico la autofagia participa en la degradación de las proteínas oxidadas durante el estrés oxidativo, en la tolerancia a la sequía y al estrés salino (Xiong et al., 2006; Liu et al., 2009). Dentro de las diferentes respuestas de la planta al estrés hídrico se encuentra la hidrotrópica que se refiere al movimiento de las raíces en busca de agua. A este proceso se le considera una estrategia adaptativa para resistir a la sequía (Cassab et al., 2013). El hidrotropismo se puede observar usando medios de cultivo con un gradiente de potencial hídrico en donde la raíz de $A$. thaliana se curva hacia la zona con más agua. Recientemente se demostró que las mutantes de la autofagia atg2, atg5, atg $8 b$, atg $8 i$ y atg9 no se curvan hacia la zona con mayor humedad. La proteína ATG2 y la proteína ATG9 son parte del complejo ATG9 que acarrea lípidos desde la membrana hasta el autofagosoma. ATG8 es esencial para la formación del autofagososma y se ha propuesto que las diferentes proteínas ATG8 como ATGb y ATG8i pueden contribuir a la diversificación de las vías de la autofagia en las plantas. También se observó la acumulación de peróxido de hidrógeno que induce a la oxidación de lípidos, tóxicos para la célula, esto podría estar relacionado con la inhibición de la curvatura durante el hidrotropismo. Los autores sugieren que la autofagia alivia el estrés oxidativo a través de la degradación de los lípidos oxidados, lo que permite que se lleve a cabo la respuesta hidrotrópica (Jiménez-Nopala et al., 2018).

La función de los genes $A T G$ también se ha estudiado en plantas con interés agronómico y los resultados de estos estudios indican que la sobreexpresión de algunos genes $A T G$ mejoran la resistencia a diferentes tipos de estrés biótico y abiótico. Como en el caso del tomate (Wang et al., 2015), tabaco (Yano et al., 2015), manzana (Wang et al., 2016), arroz (Xia et al., 2011), maíz (Chung et al., 2009), trigo (Pei et al., 2014) y plátano (Wei et al., 2017).

Debido a que las hormonas vegetales como el proceso de autofagia son fundamentales para mantener la homeostasis celular y la supervivencia de la planta durante su crecimiento $\mathrm{y}$ ante situaciones de estrés, es de importancia conocer la interrelación entre estos dos elementos.

\section{La AUtofagia Regula negativamente LA SEÑALIZACIÓN POR EL ÁCIDO SALICílICO DURANTE LA SENESCENCIA}

El ácido salicílico (SA) es una hormona vegetal que está involucrada en la respuesta de la planta al estrés abiótico 
y en la defensa contra los patógenos. El SA también puede promover la floración en Lemna gibba (lentejas de agua), y en plantas como las Zantedeschia aethiopica (alcatraz) puede desencadenar la termogénesis, un proceso que genera calor y que volatiliza aminas e indoles para atraer a los insectos polinizadores. (Buchanan et al., 2015).

En el 2009, Yoshimoto y colaboradores demostraron que el aumento en la acumulación del SA en las mutantes de autofagia $\operatorname{atg} 2$ y atg 5 indujo la muerte celular programada temprana en las hojas de Arabidopsis en condiciones óptimas de nutrientes. También demostraron que la acumulación del SA en estas mismas mutantes acelera la senescencia. Cuando se sobreexpresa el gen $N a h G$, que codifica para una hidroxilasa que convierte el SA en una forma inactiva, no hay más SA en las mutantes de autofagia y la senescencia se detiene lo que sugiere la existencia de señalización entre el SA y la autofagia. Paralelamente se observó que en las plantas tratadas con un agonista del SA: BTH (benzo thiadiazole-7-carbothioic acid) aumentó la formación de autofagosomas lo que sugiere que el SA induce la autofagia. Esta inducción de autofagosomas es dependiente del gen NPR1 (NONEXPRESSOR OF PATHOGENESISRELATED GENES1), un gen esencial en la percepción del balance del SA y jasmonatos, la mutante nprl no muestra una acumulación de autofagosomas, a diferencia de la planta silvestre. Sería interesante estudiar si también existe una interrelación entre los jasmonatos y la autofagia. Con base en lo antes descrito, se sugirió que la autofagia en una planta silvestre modula la actividad del SA durante la muerte celular programada y la senescencia.

Izumi y colaboradores (2013a) observaron que las mutantes atg crecen menos en condiciones de días cortos, en contraste crecen más en días largos, ya que al haber más horas de exposición a la luz obtiene más energía para fijar más carbono que se acumula en forma de almidón. Con base en esta observación, los autores sugieren que la autofagia provee de energía durante la noche o en condiciones de poca luz. Para demostrar su hipótesis, emplearon la doble mutante pgm/atg5 de Arabidopsis que es deficiente en la síntesis del almidón (fosfoglucomutasa, pgm) y no lleva a cabo la autofagia. La doble mutante pgm/atg5 mostró una tasa de crecimiento aún menor que la mutante atg5. Además acumula SA lo que induce a una muerte celular temprana. También acumula aminoácidos. Los autores proponen que la autofagia genera una fuente de energía a través de reciclar aminoácidos en condiciones de limitación de azúcares durante la noche, lo que permite mantener el crecimiento y la homeostasis de la planta. Como ya se mencionó, la autofagia probablemente también contribuya a inhibir la muerte celular temprana inducida por la acumulación del SA en condiciones de limitación de azúcar.

\section{LA AUTOFAgIA Y LAS GIBERELINAS DURANTE LA NOCHE REGULAN EL CRECIMIENTO VEGETAL}

Las giberelinas (GA) regulan varios procesos durante el ciclo de vida de una planta que incluyen la germinación de la semilla, el crecimiento temprano de las plántulas, expansión de las hojas, la elongación del tallo, la orientación y la senescencia de las hojas, la floración, la formación de semillas y frutos (Jones et al., 2013; Buchanan et al., 2015). La autofagia también participa en varios de estos procesos del desarrollo vegetal. Evidentemente para que todos estos procesos se desarrollen adecuadamente se requiere de energía y esqueletos de carbono proporcionados durante el día por la fotosíntesis y en la noche por la degradación del almidón acumulado en el día. Una deficiente asimilación de carbono durante el día, induce a la inanición por la noche y también a la autofagia (Izumi et al., 2013a).

Paparelli y colaboradores en 2013, demostraron que en Arabidopsis la falta de azúcar en el medio durante el día desencadena deficiencias en el metabolismo del almidón durante la noche. Estos cambios no sólo provocan la disminución de la expresión de la sintasa ent-kaurina (KS), una enzima clave en la regulación de la síntesis de las GA, sino tambien los niveles de GA y el crecimiento de las plantas, lo que provoca un fenotipo de enanismo. Mutantes con deficiencia en la síntesis y degradación del almidón como pgm y starch excess 1-1 (sexl-1), también tienen un fenotipo de enanismo, lo que se asemeja al fenotipo de una planta silvestre en condiciones de inanición por falta de carbono. Las mutantes pgm y sexl-1 tienen niveles bajos de KS y GA comparados con la planta silvestre sin azúcar en el medio. El fenotipo de enanismo en las mutantes pgm y sexl-1 se elimina al incrementar la intensidad de la luz, ya que esto aumenta la tasa de la fotosíntesis, los niveles de carbohidratos y GA durante el día. La autofagia durante la noche provee de esqueletos de carbono, a través del reciclamiento de aminoácidos (Izumi et al., 2013b). Estos resultados indicaron que la autofagia contribuye al crecimiento de las plantas durante la noche cuando la síntesis de GA disminuye debido a una deficiente asimilación de carbohidratos durante el día.

\section{LA AUTOFAgIA DURANTE EL DESARROLlO DE LAS ANTERAS REGULA LA CONCENTRACIÓN DE LAS CITOCININAS Y LAS GIBERELINAS}

La zeatina es una hormona vegetal, que pertenece al grupo de las citocininas, cuya función principal es estimular la división celular en tejidos no meristemáticos que se sintetiza en los plastidios y es transportada por el xilema (Jones et al., 2013). Los niveles de endógenos de formas activas de las giberelinas y citocininas en la mutante del gen ATG7 en Oriza sativa (Osatg7-1) disminuyen considerablemente comparando con la planta silvestre, lo que ocasiona un fenotipo de esterilidad 
en las anteras (órgano masculino de la flor) durante la etapa de floración. Este fenotipo de esterilidad se propone que se debe a defectos en la vía de síntesis del precursor biológico de las GA ent-kaurene en la mutante Osatg7-1. En este mismo trabajo también se encontraron niveles bajos de citocininas, sin embargo, no se ha aclarado cómo la autofagia regula los niveles de esta hormona durante el desarrollo de las anteras (Kurusu et al., 2017).

Interesantemente en 2008, Slavikova y colaboradores, emplearon plantas de Arabidopsis que expresan la fusión GFPATG8f como marcador de los autofagosomas y observaron que la zeatina inhibe la incorporación de los autofagosomas en las vacuolas de las células de la epidermis de la raíz y en las células cercanas al floema. En estas mismas plantas se observó una disminución en el crecimiento de la raíz primaria, mientras que en las raíces adventicias, raíces que surgen del tallo y sirven de soporte a la planta, incrementan su número. Los autores concluyen que la zeatina inhibe la autofagia, ya que impide el flujo y la degradación de los autofagosomas en la vacuola afectando el crecimiento del sistema radicular de la planta. Con base en estos resultados, sugerimos que la zeatina puede actuar como un inhibidor químico de la autofagia lo que afecta el desarrollo del sistema radicular.

\section{EL ESTRÉS HÍDRICO REGULA LA INDUCCIÓN DEL ABA Y ETILENO SIMULTÁNEAMENTE A LA ACTIVACIÓN DE LA AUTOFAGIA}

ABA es la hormona vegetal por excelencia involucrada en las respuestas de las plantas al estrés abiótico, como la sequía y uno de sus efectos es el cierre rápido de los estomas para impedir la pérdida de agua (Jones et al., 2013).

En Solanum lycopersicum (tomate) uno de los reguladores de la respuesta al estrés por sequía de la planta es el factor transcripcional HsfAla. Wang y colaboradores (2015), observaron que al silenciar el gen HsfAla se incrementa el cierre de los estomas bajo estrés por sequía y aumenta la acumulación de los niveles de ABA. En este estudio se demostró que HsfAla induce tolerancia a la sequía al activar los genes $A T G$ e inducir la autofagia. HsfAla se une y regula positivamente la expresión de $A T G 10$ y $A T G 18 f$, lo que induce la formación de autofagosomas. Lo anterior, lleva a un aumento de la autofagia para promover la degradación de los agregados de proteínas ubiquitinadas insolubles producidas en la sequía y que son tóxicas para las células, incrementando así la supervivencia celular (Wang et al., 2015). Aunque en este trabajo se observó una regulación del cierre de estomas y un incremento en los niveles de ABA a través del silenciamiento del gen HsfAla, no se demostró que ABA regula la autofagia. Además, la adición directa de ABA a las plantas no induce la autofagia como tampoco en las mutantes de la biosíntesis de ABA, por lo tanto la inducción de autofagia en respuesta al estrés osmótico es independiente de ABA (Liu et al., 2009).

La otra hormona que se induce en las plantas en respuesta al estrés hídrico es el etileno. El etileno es un hidrocarburo simple, insaturado y volátil. Esta hormona regula el desarrollo de hojas, flores y frutas. También puede inhibir o inducir la senescencia dependiendo de si sus niveles son óptimos o subóptimos (Iqbal et al., 2017). El etileno afecta muchos aspectos del desarrollo de la planta, como la abscisión de las hojas y otros órganos, estimula la maduración de la fruta, promueve la germinación y afecta la expansión celular. La respuesta al etileno en las plántulas incluye la flexión y el engrosamiento del tallo y el rizado del gancho apical. El etileno se sintetiza en casi todos los tejidos de las plantas, pero su tasa de síntesis se incrementa en respuesta a la herida y otros tipos de estrés. Es fundamental para la senescencia, la abscisión y la maduración de la fruta. Algunas frutas maduras como el plátano producen grandes cantidades de etileno y se les denomina frutas climatéricas (Jones et al., 2013).

La inducción de ABA y etileno en respuesta al estrés hídrico va acompañada de la inducción de peróxido de hidrógeno que en bajas cantidades señaliza para activar procesos celulares, pero en cantidades grandes ocasiona daño. En $S$. lycopersicum, un nivel bajo de etileno induce la autofagia y la actividad de la oxidasa alternativa mitocondrial (AOX, mitochondrial Alternative Oxidase), que controla los productos de la oxidación de la cadena transportadora de electrones de la mitocondria y es esencial para que se induzca la tolerancia al estrés hídrico mediada por etileno. La actividad de la AOX provoca la disminución del peróxido de hidrógeno lo que induce a la autofagia para degradar los productos oxidados por el exceso de especies reactivas de oxígeno (ROS) provocadas por el estrés hídrico. En este trabajo, también se demostró que se requiere de la proteína ERF5 (Ethylen Response Factor) que reconoce elementos de regulación por etileno en los promotores de los genes de la autofagia $A T G 8 d$ y $A T G 18 h$. Estos resultados demostraron que el etileno regula la inducción de la AOX y también los niveles de peróxido de hidrógeno lo que permite la inducción de la autofagia. Todos estos elementos son esenciales en la tolerancia a la sequía de plantas como el tomate.

\section{El ETILENO Y LA AUTOFAgia DURANTE LA POLINIZACIÓN SE INDUCEN EN LOS PÉTALOS}

En estudios previos en Petunia híbrida $(P h)$, se demostró que la autofagia, analizada como la acumulación del mRNA de $P h A T G 8$, se activa en las células de la epidermis de los pétalos senescentes de las petunias paralelamente a los niveles de etileno en las flores polinizadas. Así mismo, el etileno induce la polinización que acelera la inducción de PhATG8. Estos resultados indicaron que el etileno regula la expresión del gen PhATG8. En este mismo trabajo se observó que en la senescencia, los nutrientes se movilizan desde los pétalos hasta los ovarios durante la polinización y 
que la autofagia es la responsable de la movilización de estos nutrientes, ya que cuando se inhibe la autofagia el peso seco de los ovarios en las flores polinizadas es menor que el de los ovarios de las flores control (Shibuya et al., 2013). Los resultados sugieren que la autofagia moviliza nutrientes para el buen desarrollo de los ovarios vía la inducción de etileno durante la polinización.

\section{LAS AUXINAS Y TOR}

La célula vegetal almacena nutrientes en forma de almidón, proteínas y lípidos para asegurar la homeostasis. Estas reservas se movilizan cuando hay escasez de nutrientes. Como se mencionó anteriormente, la autofagia es uno de los procesos a través del cual las plantas producen energía y nutrientes en tiempos de escasez. La inanición en las plantas activa al complejo SnRK1 cuya cinasa fosforila al ATG1 que es el control principal para el inicio de la autofagia. Por el contrario, el complejo antagonista TOR, conformado por la cinasa TOR, la proteína RAPTOR y la proteína LST8, inhiben la autofagia a través de la fosforilación de ATG13 lo que previene su asociación con ATG1. TOR actúa de forma antagónica a SnRK1 a través de la interacción entre la subunidad KIN10 del complejo SnRK1 que fosforila a RAPTOR del complejo TOR. (Marshall \& Viestra, 2018; Dobrenel et al., 2016).

A diferencia de los mecanismos moleculares bien descritos que relacionan a TOR con nutrientes en mamíferos y levaduras, en las plantas hay poca información de los mismos. Hasta la fecha, se ha observado que algunos componentes de la vía de regulación de TOR no están conservados en las plantas, como TSC1/2, la proteína Rheb, PI3K clase I-II y la fosfocinasa B (van Dam et al., 2011; Soto-Burgos \& Bassham, 2017). Es probable que las plantas involucren a las hormonas vegetales en sus mecanismos de señalización específicos por ejemplo, interactuando con receptores sensibles a los niveles de energía y nutrientes. La interrelación de las auxinas y TOR es uno de los ejemplos más claros del acoplamiento de la señalización por hormonas vegetales y TOR, se demostró que las auxinas inducen el complejo TOR, así como la inactivación de la autofagia; también se demostró la contribución de la actividad de TOR a los procesos mediados por la señalización de auxina río abajo (Bögre et al., 2013).

En 2013, Schepetilnikov y colaboradores demostraron en Arabidopsis que las auxinas desencadenan la activación de TOR, lo que promueve la fosforilación de la cinasa S6K1, que fosforila proteínas indispensables para la iniciación de la traducción con la percepción de niveles de energía, los nutrientes y las hormonas como eIF3h. Las auxinas además de estar relacionadas con la activación de TOR, son un grupo de hormonas vegetales que regulan muchos de los aspectos del desarrollo de la planta: desde la polinización y la fertilización, hasta el desarrollo vegetativo y la floración. Las auxinas son moléculas clave en la señalización de las respuestas trópicas de las plantas como lo son la gravedad, la luz y el tacto, además de participar en la síntesis y acción de otras hormonas vegetales (Weijers \& Wagner, 2016; Jones et al., 2013), lo que implica que sus efectos sobre el crecimiento, desarrollo de las plantas y la autofagia son más amplios de lo que hasta ahora se ha descrito.

\section{LA AUTOFAgia Y LAS AUXINAS DURANTE EL HIDROTROPISMO SE REGULAN DIFERENCIALMENTE}

En condiciones óptimas de nutrientes, las auxinas promueven el crecimiento, desarrollo en la planta y activan a TOR, por lo que estas hormonas regulan negativamente la autofagia.

Anteriormente, se demostró que la autofagia se induce durante el hidrotropismo como una respuesta al estrés hídrico y se ha propuesto que provee de energía a las células, ya que degrada los amiloplastos de la cofia de la raíz (Nakayama et al., 2012). Previamente se demostró que las auxinas no se requieren para la curvatura hidrotrópica (Shkolnik et al., 2016), mientras que recientemente se comprobó que la autofagia es indispensable para que se lleve a cabo el hidrotropismo (Jiménez-Nopala et al., 2018) (Figura 2). Adicionalmente, no se detectó ninguna señal de la GFP fusionada al indicador transcripcional de la

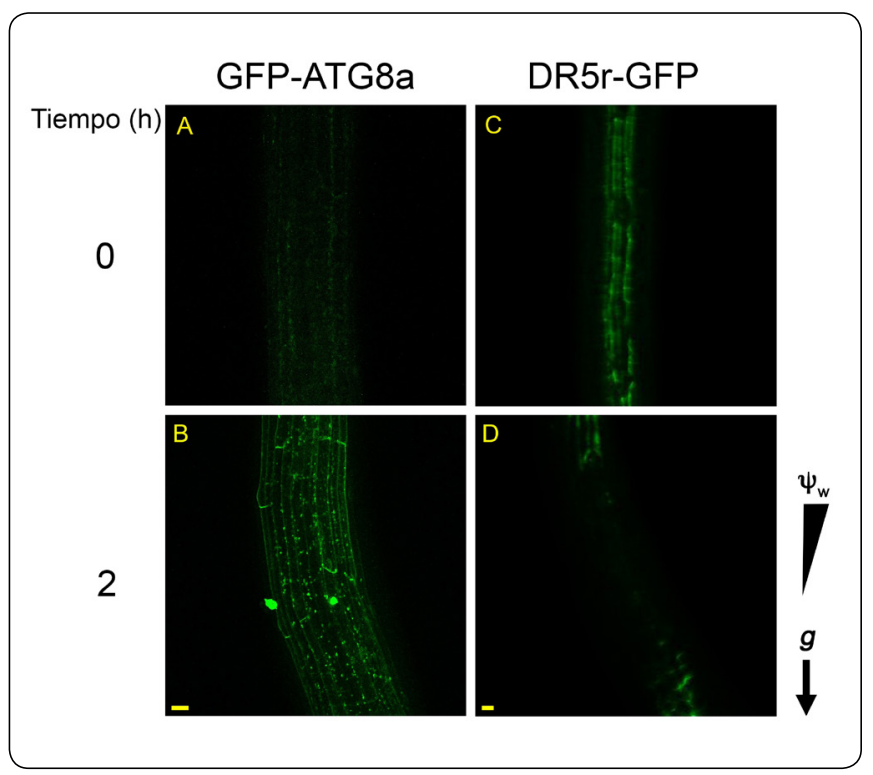

Figura 2. Las auxinas están ausentes mientras que los autofagosomas se acumulan en la zona de la curvatura durante la respuesta hidrotrópica. Plántulas de GFP-ATG8 de 4 días después de la germinación (dpg) en el medio hídrico estresante, A) a las 0 $h$ en donde no se observan los puntos verdes que representan a los autofagosomas y B) a las $\mathbf{2}$ horas donde se observa la acumulación de autofagosomas en la zona de curvatura. Plántulas de DR5rGFP de 4 dpg C) a las 0 h en donde se observa la acumulación de auxinas y D) a las 2 h en donde no se observa acumulación de las auxinas en la zona de la curvatura en el medio hídrico estresante. Las imágenes se obtuvieron con técnicas de microscopía confocal. A, objetivo seco $40 \mathrm{X}, \mathrm{y}$ B, objetivo seco 10X. g, gravedad. $\Psi_{\mathrm{w}}$, potencial hídrico. Barra de la escala $10 \mu \mathrm{m}$. 
respuesta a auxinas (DR5r::GFP), en la zona de la curvatura donde se reportó la acumulación de autofagosomas. Como se mencionó, las auxinas participan en la activación del complejo TOR, que es un regulador negativo de la autofagia, por lo que niveles bajos de auxinas implican una regulación negativa del complejo TOR y la activación de la autofagia durante el hidrotopismo.

\section{CONCLUSIONES}

La autofagia, participa en diferentes etapas del desarrollo de las plantas y en respuesta al estrés biótico y abiótico. En todos estos procesos se ha demostrado que también participan las diferentes hormonas vegetales. Sin embargo, a pesar del progreso realizado en la investigación de la autofagia en plantas y del extenso conocimiento acerca del funcionamiento de las hormonas vegetales, varias preguntas clave permanecen abiertas. No existe información suficientemente clara que indique si las hormonas vegetales inducen a la autofagia directamente o si alguna de las moléculas de reciclamiento obtenidas en el proceso de autofagia regula a las hormonas vegetales. Este es un campo de investigación que en el futuro podrá aportar más información acerca de estos procesos. En la Figura 3 se resume la información compilada en esta revisión.

\section{Agradecimientos}

Las autoras agradecen el apoyo del CONACYT (179333); DGAPA (IN206714-3 y IN202417). Gladys Jiménez Nopala contó con el apoyo de una beca de doctorado del CONACYT. Agradecemos al Dr. Jiri Frimi la donación de las semillas DR5r::GFP.

\section{REFERENCIAS}

Avin-Wittenberg, T., Hoing, A. \& Galili, G., (2012). Variations on a Theme: Plant Autophagy in Comparison to Yeast and Mammals. Protoplasma, 249 (2), 285-299. DOI:10.1007/s00709-0110296-z.

Bassham, D. C., Laporte, M., Marty, F., Moriyasu, Y., Ohsumi, Y., Olsen, L. J., \& Yoshimoto, K. (2006). Autophagy in development and stress responses of plants. Autophagy, 2-11. DOI.org/10.4161/auto.2092.

Bögre, L., Henriques, R., \& Magyar, Z. (2013). TOR Tour to Auxin. The EMBO Journal, 32(8), 1069-1071. DOI:10.1038/ emboj.2013.69.

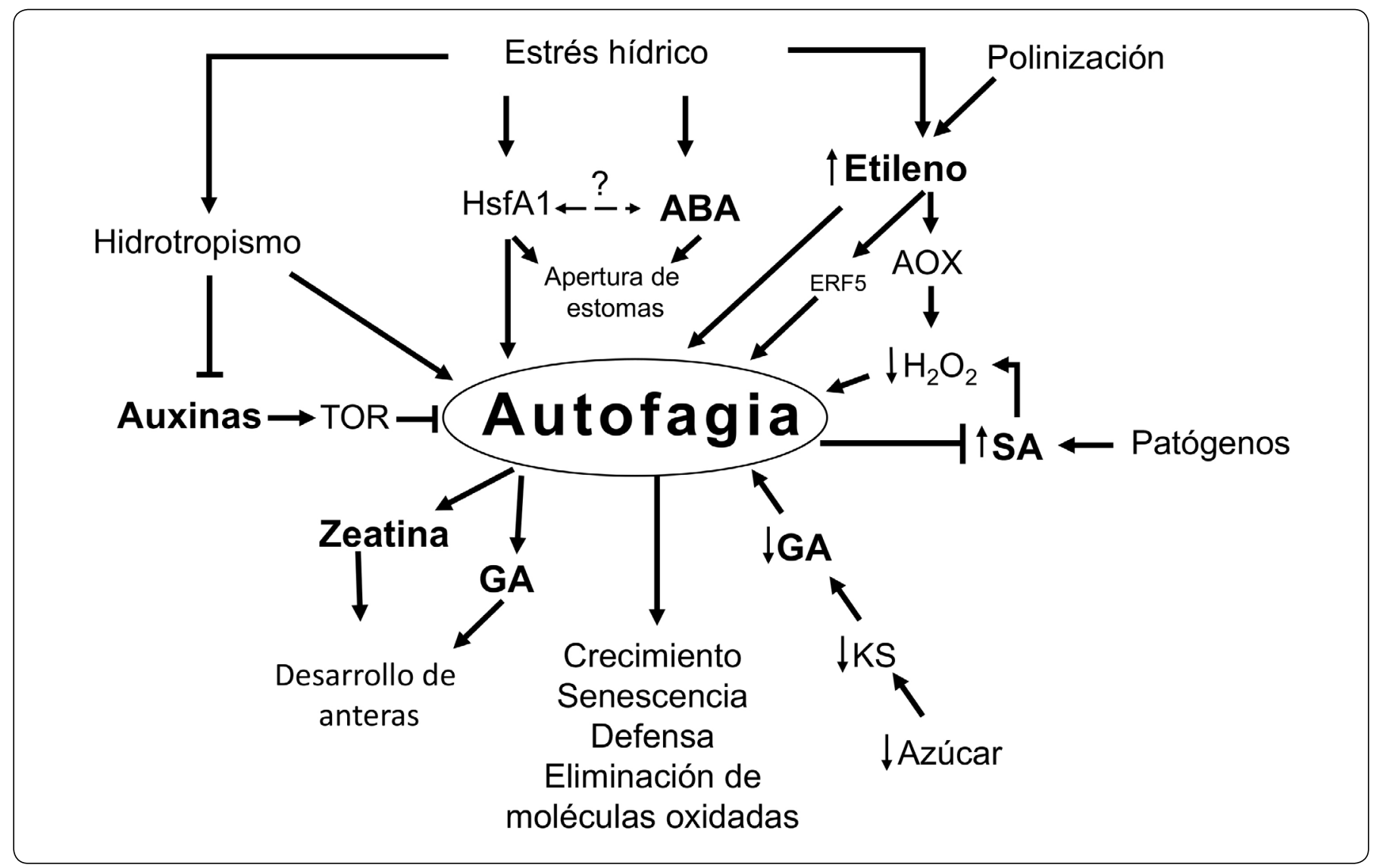

Figura 3. La interrelación entre la autofagia y las hormonas vegetales. En este resumen gráfico se muestra que la autofagia y las hormonas vegetales ABA, etileno, GA, auxinas, zeatina o SA coinciden en diferentes procesos durante el desarrollo de las plantas y en respuesta al estrés como: la polinización, el ataque por patógenos, disminución en los niveles de azúcar durante el desarrollo de las anteras y en respuesta al estrés hídrico y el hidrotropismo. Fuente: Elaboración propia. 
Bozhkov, P. V., Filonova, L. H., \& Suárez, M. F. (2005). Programmed Cell Death in Plant Embryogenesis. Current Topics in Developmental Biology, 135-179. DOI:10.1016/s00702153(05)67004-4.

Buchanan, B. B., Jones, R. L., \& Gruissem, W. (2015). Biochemistry \& molecular biology of plants. American Society of Plant Biologists. Wiley, New York.

Chung, T., Suttangkakul, A., \& Vierstra, R. D. (2009). The ATG Autophagic Conjugation System in Maize: ATG Transcripts and Abundance of the ATG8-Lipid Adduct Are Regulated by Development and Nutrient Availability. Plant Physiology, 149, 220-234. DOI:10.1104/pp.108.126714.

Cassab, G., Eapen, D., \& Campos, M. E. (2013). Root Hydrotropism: An Update. American Journal of Botany, 100(1), 2012, 14-24. DOI:10.3732/ajb.1200306.

Dobrenel, T., Caldana, C., Hanson, J., Robaglia, C., Vincentz, M., Veit, B., \& Meyer, C. (2016). TOR Signaling and Nutrient Sensing. Annual Review of Plant Biology, 67(1), 261-285., DOI:10.1146/annurev-arplant-043014-114648.

Finkelstein, R. R. (2010). The Role of Hormones during Seed Development and Germination. Plant Hormones, 549-573. DOI:10.1007/978-1-4020-2686-7 24.

Fujiki, Y., Yoshimoto, K., \& Ohsumi, Y. (2007). An Arabidopsis Homolog of Yeast ATG6/VPS30 Is Essential for Pollen Germination. Plant Physiology, 143, 1132-1139. DOI:10.1104/ pp.106.093864.

Hayward, A. P., Tsao, J., \& Dinesh-Kumar, S. (2009). Autophagy and plant innate immunity: Defense through degradation. Seminars in Cell \& Developmental Biology, 20, 1041-1047. DOI:10.1016/j.semcdb.2009.04.012.

Inoue, Y., Suzuki, T., Hattori, M., Yoshimoto, K., Ohsumi, Y., \& Moriyasu, Y. (2006). AtATG Genes, Homologs of Yeast Autophagy Genes, are Involved in Constitutive Autophagy in Arabidopsis Root Tip Cells. Plant and Cell Physiology, 47, 1641-1652. DOI:10.1093/pcp/pc1031.

Iqbal, N., Khan, N. A., Ferrante, A., Trivellini, A., Francini, A., \& Khan, M. I. R. (2017). Ethylene Role in Plant Growth, Development and Senescence: Interaction with Other Phytohormones. Frontiers in Plant Science, 8. DOI:10.3389/ fpls.2017.00475.

Izumi, M., Hidema, J., Makino, A., \& Ishida, H. (2013a). Autophagy Contributes to Nighttime Energy Availability for Growth in Arabidopsis. Plant Physiology, 161, 1682-1693. DOI:10.1104/ pp.113.215632.

Izumi, M., Hidema, J., \& Ishida, H. (2013b). Deficiency of autophagy leads to significant changes of metabolic profiles in Arabidopsis. Plant Signaling \& Behavior, 8. DOI:10.4161/psb.25023.

Jiménez-Nopala, G., Salgado-Escobar, A. E., Cevallos-Porta, D., Cárdenas, L., Sepúlveda-Jiménez, G., Cassab, G., \& Porta, H. (2018). Autophagy mediates hydrotropic response in Arabidopsis thaliana roots. Plant Science, 272, 1-13. DOI:10.1016/j.plantsci.2018.03.026.

Jiménez, V. M. (2005). Involvement of Plant Hormones and Plant Growth Regulators on in vitro Somatic Embryogenesis. Plant Growth Regulation, 47, 91-110. DOI:10.1007/s10725-0053478-x.

Jones, R. L., Ougham, H., Thomas, H., \& Waaland, S. (2013). The molecular life of plants. Wiley-Blackwell.

Kurusu, T., Koyano, T., Kitahata, N., Kojima, M., Hanamata, S.,
Sakakibara, H., \& Kuchitsu, K. (2017). Autophagy-mediated regulation of phytohormone metabolism during rice anther development. Plant Signaling \&amp; Behavior, 12. DOI:10.10 80/15592324.2017.1365211.

Kwon, S. I., Cho, H. J., Jung, J. H., Yoshimoto, K., Shirasu, K., \& Park, O. K. (2010). The Rab GTPase RabG3b functions in autophagy and contributes to tracheary element differentiation in Arabidopsis. The Plant Journal, 64, 151-164. DOI:10.1111/ j.1365-313x.2010.04315.x.

Lai, Z., Wang, F., Zheng, Z., Fan, B., \& Chen, Z. (2011). A critical role of autophagy in plant resistance to necrotrophic fungal pathogens. The Plant Journal, 66, 953-968. DOI:10.1111/ j.1365-313x.2011.04553.x.

Li, F., Chung, T., \& Vierstra, R. D. (2014). AUTOPHAGYRELATED11 Plays a Critical Role in General Autophagy- and Senescence-Induced Mitophagy in Arabidopsis. The Plant Cell, 26, 788-807. DOI:10.1105/tpc.113.120014.

Liu, Y., Xoing, Y., \& Bassham, D. (2009). Autophagy Is Required for Tolerance of Drought and Salt Stress in Plants. Autophagy, 5(7), 954-963., DOI:10.4161/auto.5.7.9290.

Marshall, R. S., \& Vierstra, R. D. (2018). Autophagy: The Master of Bulk and Selective Recycling. Annual Review of Plant Biology, 69, 173-208. DOI:10.1146/annurev-arplant-042817-040606.

Nakayama, M,. Kaneko, Y., Miyazawa, Y., Fujii, N., Higashitani, N., Wada, S., Ishida, H., Yoshimoto, K., Shirasu, K., Yamada, K., Nishimura, M., \& Takahashi, H., (2012). A Possible Involvement of Autophagy in Amyloplast Degradation in Columella Cells during Hydrotropic Response of Arabidopsis Roots. Planta, 236(4), 999-1012. DOI:10.1007/s00425-012-1655-5.

Paparelli, E., Parlanti, S., Gonzali, S., Novi, G., Mariotti, L., Ceccarelli, N., van Dongen, J. T., Kölling, K., Zeeman, S. C., \& Perata, P. (2013). Nighttime Sugar Starvation Orchestrates Gibberellin Biosynthesis and Plant Growth in Arabidopsis. The Plant Cell, 25, 3760-3769. DOI:10.1105/tpc.113.115519.

Parzych, K. R., \& Klionsky, D. J. (2014). An Overview of Autophagy: Morphology, Mechanism, and Regulation. Antioxidants \& Redox Signaling, 20, 460-473. DOI:10.1089/ars.2013.5371.

Pei, D., Zhang, W., Sun, H., Wei, X., Yue, J., \& Wang, H. (2014). Identification of autophagy-related genes ATG4 and ATG8 from wheat (Triticum aestivum L.) and profiling of their expression patterns responding to biotic and abiotic stresses. Plant Cell Reports, 33, 1697-1710. DOI:10.1007/s00299-014-1648-x.

Rose, T. L., Bonneau, L., Der, C., Marty-Mazars, D., \& Marty, F. (2006). Starvation-induced expression of autophagyrelated genes in Arabidopsis. Biology of the Cell, 98, 53-67. DOI: $10.1042 / \mathrm{bc} 20040516$.

Santner, A., \& Estelle, M. (2009). Recent advances and emerging trends in plant hormone signalling. Nature, 459, 1071-1078. DOI:10.1038/nature08122.

Schepetilnikov, M., Dimitrova, M., Mancera-Martínez, E., Geldreich, A., Keller, M. \& Ryabova, L. (2013). TOR and S6K1 Promote Translation Reinitiation of UORF-Containing MRNAs via Phosphorylation of eIF3h. The EMBO Journal, 32(8), 10871102. DOI:10.1038/emboj.2013.61.

Shibuya, K., Niki, T. \& Ichimura., K. (2013). Pollination induces autophagy in petunia petals via ethylene. Journal of Experimental Botany, 64(4),1111-1120. DOI.org/10.1093/jxb/ers395.

Shkolnik, D., Krieger, G., Nuriel, R., \& Fromm, H. (2016). Hydrotropism: Root Bending Does Not Require Auxin 
Redistribution. Molecular Plant, 9, 757-759. DOI:10.1016/j. molp.2016.02.001.

Slavikova, S., Ufaz, S., Avin-Wittenberg, T., Levanony, H., \& Galili, G. (2008). An autophagy-associated Atg8 protein is involved in the responses of Arabidopsis seedlings to hormonal controls and abiotic stresses. Journal of Experimental Botany, 59, 4029 4043. DOI:10.1093/jxb/ern244.

Soto-Burgos, J., \& Bassham, D. C. (2017). SnRK1 activates autophagy via the TOR signaling pathway in Arabidopsis thaliana. Plos One, 12(8), e0182591. DOI:10.1371/journal. pone.0182591.

van Dam, T. J. P., Zwartkruis, F. J. T., Bos, J. L., \& Snel, B. (2011). Evolution of the TOR Pathway. Journal of Molecular Evolution, 73, 209-220. DOI:10.1007/s00239-011-9469-9.

van Doorn, W. G., \& Woltering, E. J. (2005). Many ways to exit? Cell death categories in plants. Trends in Plant Science, 10, 117-122. DOI:10.1016/j.tplants.2005.01.006.

Wada, S., Ishida, H., Izumi, M., Yoshimoto, K., Ohsumi, Y., Mae, T., \& Makino. A. (2009). Autophagy Plays a Role in Chloroplast Degradation during Senescence in Individually Darkened Leaves. Plant Physiology, 149, 885-893. DOI:10.1104/ pp.108.130013.

Wang, P., Sun, X., Jia, X., Wang, N., Gong, X., \& Ma, F. (2016). Characterization of an Autophagy-Related Gene MdATG8i from Apple. Frontiers in Plant Science, 7(720), 1-16. DOI:10.3389/ fpls.2016.00720.

Wang, Y. \& Liu, Y. (2013). Autophagic Degradation of Leaf Starch in Plants. Autophagy, 9. 1247-1248. DOI:10.4161/auto.25176.

Wang, Y., Cai, S., Yin, L., Shi, K., Xia, X., \& Zhou, Y., (2015). Tomato HsfA1a plays a critical role in plant drought tolerance by activating ATG genes and inducing autophagy. Autophagy, 11, 2033-2047. DOI:10.1080/15548627.2015.1098798.

Wei, Y., Liu, W., Hu, W., Liu, G., Wu, C., Liu, W., Zeng, H., He, C., \& Shi, H. (2017). Genome-wide analysis of autophagyrelated genes in banana highlights MaATG8s in cell death and autophagy in immune response to Fusarium wilt. Plant Cell Reports, 36, 1237-1250. DOI:10.1007/s00299-017-2149-5.

Weijers, D. \& Wagner, D. (2016). Transcriptional Responses to the Auxin Hormone. Annual Review of Plant Biology, 67(1), 539574. DOI:10.1146/annurev-arplant-043015-112122.

Xia, K., Liu, T., Ouyang, J., Wang, R., Fan, T., \& Zhang, M. (2011). Genome-Wide Identification, Classification, and Expression Analysis of Autophagy-Associated Gene Homologues in Rice (Oryza sativa L.). DNA Research, 18, 363-377. DOI:10.1093/ dnares/dsr024.

Xiong, Y., Contento, A. L., Nguyen, P. Q., \& Bassham, D. C. (2006). Degradation of Oxidized Proteins by Autophagy during Oxidative Stress in Arabidopsis. Plant Physiology, 143, 291299. DOI:10.1104/pp.106.092106.
Xiong, Y., Contento, A. L., \& Bassham, D. C. (2005). AtATG18a is required for the formation of autophagosomes during nutrient stress and senescence in Arabidopsis thaliana. The Plant Journal, 42, 535-546. DOI:10.1111/j.1365-313x.2005.02397.x.

Yang, X., \& Bassham, D. C. (2015). New Insight into the Mechanism and Function of Autophagy in Plant Cells. International Review of Cell and Molecular Biology, 1-40. DOI:10.1016/ bs.ircmb.2015.07.005.

Yang, Z. \& Klionsky, D.J. (2009). An Overview of the Molecular Mechanism of Autophagy. In: Levine, B., Yoshimori, T., Deretic, V. (eds) Autophagy in Infection and Immunity. Current Topics in Microbiology and Immunology, Vol. 335. Springer, Berlin, Heidelberg. DOI:10.1007/978-3-642-00302-8_1

Yang, Z., \& Klionsky, D.J. (2010). Eaten alive: a history of macroautophagy. Nature Cell Biology, 12, 814-822. DOI:10.1038/ncb0910-814

Yano, K., Suzuki, T., \& Moriyasu, Y. (2007). Constitutive Autophagy in Plant Root Cells. Autophagy, 3, 360-362. DOI:10.4161/ auto.4158.

Yano, K., Yanagisawa, T., Mukae, K., Niwa, Y., Inoue, Y., \& Moriyasu, Y. (2015). Dissection of autophagy in tobacco BY-2 cells under sucrose starvation conditions using the vacuolar $\mathrm{H}$ -ATPase inhibitor concanamycin A and the autophagy-related protein Atg8. Plant Signaling \& Behavior, 10. ODI:10.1080/15 592324.2015.1082699.

Yoshimoto, K., Hanaoka, H., Sato, S., Kato, T., Tabata, S., Noda, T. \& Ohsumi, Y. (2004). Processing of ATG8s, Ubiquitin-Like Proteins, and Their Deconjugation by ATG4s Are Essential for Plant Autophagy. The Plant Cell Online. 16(11), 2967-2983. DOI:10.1105/tpc.104.025395.

Yoshimoto, K., Jikumaru, Y., Kamiya, Y., Kusano, M., Consonni, C., Panstruga, R., \& Ohsumi, Y., Shirasu. K. (2009). Autophagy Negatively Regulates Cell Death by Controlling NPR1Dependent Salicylic Acid Signaling during Senescence and the Innate Immune Response in Arabidopsis. The Plant Cell Online, 21, 2914-2927. DOI:10.1105/tpc.109.068635.

Yoshimoto, K. (2012). Beginning to understand autophagy, an intracellular self-degradation system in plants. Plant Cell Physiol 53(8): 1355-1365. DOI:10.1093/pcp/pcs099

Zhu, T., Zou, L., Li, Y., Yao, X., Xu, F., Deng, X., Zhang, D., \& Lin H. (2018). Mitochondrial alternative oxidase-dependent autophagy involved in ethylene-mediated drought tolerance in Solanum lycopersicum. Plant Biotechnology Journal. DOI:10.1111/ pbi.12939.

Zhuang, X., Chung, K., Cui, Y., Lin, W., Gao, C., Kang, B. \& Jiang, L. (2017). ATG9 Regulates Autophagosome Progression from the Endoplasmic Reticulum In Arabidopsis. Proceedings of the National Academy of Sciences, 114(3), DOI:10.1073/ pnas. 1616299114. 